\title{
Systematic Literature Review Penggunaan Layanan Telemedicine di Indonesia
}

\author{
Dedy Dwiputra $^{1}$ \\ Magister Ilmu Komputer, Universitas Esa Unggul Jakarta \\ Jalan Arjuna Utara No.9, Kebon Jeruk 11510 , Jakarta Barat, DKI Jakarta , Indonesia \\ ${ }^{1}$ Dedy.dwiputradstudent. esaunggul.ac.id
}

\begin{abstract}
ABASTRAKSI
Kemajuan di bidang teknologi informasi dimanfaatkan juga pada bidan kesehatan, salah satunya layanan medis online yang memungkinkan dokter atau tenaga medis memberikan pelayanan kesehatan dari jarak jauh yang disebut dengan Telemedicine. Salah satu penyedia layanan telemedicine adalah Halodoc, Alodoc dan KlikDokter.

Agar dapat terus bersaing dengan para pemain telemedicine lainn. Saat ini banyak penelitian yang meneliti isu yang mempengaruhi penggunaan layanan telemedicine. Sehingga diperlukan review terhadap paper jurnal yang membahas tentang penggunaan layanan telemedicine. Metode yang digunakan oleh penulis dalam penelitian ini adalah Systematic Literature Review (SLR) terhadap paper jurnal yang publish dari tahun 2017-2021. Terdapat tiga Research Question (RQ) yang ditetapkan pada penelitian ini. Serta hasil akhir yang diperoleh dari penelitian ini adalah tantangan yang masih di hadapi oleh telemedicine terutama dalam hal isu penggunaan layanan telemedicine, serta perbandingan antara keadaan yang terjadi dengan teori yang ada. telemedicine yang banyak diteliti yaitu Halodoc teknik pengumpulan data yang digunakan adalah kuesioner dan observasi. Hasil yang didapatkan pada penelitian ini diharapkan dapat memberikan informasi agar para penyedia layanan telemedicine terus meningkatkan kualitas pelayanannya sehingga meningkatkan kinerja dari layanan yang berakibat pada loyalitas dan penggunaan ulang jasa tersebut.
\end{abstract}

Kata kunci - permasalahan, telemedicine, Halodoc, Alodoc, SLR, Survey

\section{PENDAHULUAN}

Seiring dengan perkembangan zaman, ilmu pengetahuan dan teknologi juga semakin berkembang. Demikian juga teknologi di bidang kedokteran, salah satunya adalah telemedicine. Telemedicine dapat diartikan sebagai proses pengobatan (meliputi diagnosis dan terapi) dari jarak jauh. Proses tersebut menggunakan jaringan telekomunikasi khususnya adalah internet, sehingga dapat menghubungkan tempat yang satu dengan yang lain. Telemedicine dapat digunakan untuk mengirimkan gambar, grafik dan datadata medis dari satu tempat ke tempat yang lain. Selain itu memungkinkan konsultasi secara langsung seperti berada ditempat yang sama (van Bemmel, Musen, 1997; Coiera, 1997; Olver, 2001).

Telemedicine sangat berguna bagi dokter-dokter yang sering bertugas diluar tempat praktek, tetapi sangat dibutuhkan konsultasinya mengenai kasus-kasus penyakit tertentu ketika ia sedang bertugas diluar tempat prakteknya. Selain itu untuk daerah-daerah terpencil yang kurang atau tidak ada sarana pelayanan kesehatan, karena daerah tersebut sulit dijangkau. Telemedicine dapat digunakan sebagai sarana konsultasi medis antara dokter dengan dokter, dokter dengan perawat, atau dokter dengan pasien melalui teknologi telekomunikasi. Hal tersebut berpotensi besar untuk meningkatkan derajat kesehatan masyarakat di daerah yang tidak/kurang dapat dijangkau oleh sarana pelayanan kesehatan (Coiera, 1997; Manning, 1997; Okoromah, Afolabi, 2005).

Pada penelitian yang dilakukan Cynthia Fransiska dan Innocentius Bernato (2021) yang berjudul "Pengaruh Kualitas Layanan terhadap Kepuasan Pelanggan dan Keberlanjutan Penggunaan pada Pengguna Aplikasi Kesehatan". pengguna aplikasi Halodoc yang mengisi kuesioner yang disebar dengan menggunakan Google form. Unit analisis pada penelitian ini adalah individu dengan subjek penelitian merupakan pengguna aplikasi kesehatan Halodoc di Indonesia. Penelitian ini menggunakan convenience sampling yang masuk kedalam nonprobabilitas sampling. Karena populasi penelitian tidak diketahui sehingga penentuan jumlah sampel akan menggunakan metode inverse square root yang merupakan jumlah sampel minimal untuk penelitian menggunakan partial least square structural equation modelling (PLSSEM) yaitu 160 (Kock dan Hadaya, 2018). Jumlah sampel yang digunakan dalam penelitian ini adalah sebanyak 190 orang $^{[1]}$.

Kesimpulan yang dapat diambil dari penelitian diatas adalah kualitas pelayanan berpengaruh terhadap kepuasan pelanggan dan kepuasan pelanggan berpengaruh terhadap penggunaan layanan telemedicine. Sehingga pada penelitian ini kami akan menggunakan metode Systematic Literature Review untuk me-review penelitian-penelitain sebelumnya tentang penggunaan layanan telemedicine sehingga dapat menjadi referensi para pengembang bisnis telemedicine untuk dapat meningkatkan layanan, sehingga meningkatkan penggunaan dari layanan itu sendiri. 


\section{METODE PENELITIAN}

Tahapan dalam penelitian ini merujuk pada penelitian yang dilakukan oleh E. Triandini, S. Jayanatha, A. Indrawan, G. W. Putra dan B. Iswara pada tahun 2019 yaitu $^{[8]}$ :

\subsection{Objek Penelitian}

Objek dalam penelitian ini adalah kepuasan pelanggan terhadap penggunaan layanan telemedicine. Diambilnya kepuasan pelanggan sebagai objek penelitian karena faktor-faktor yang mempengaruhi kepuasan pelanggan sangat beragam dan dapat menjadi pertimbangan para penyedia layanan telemedicine untuk meningkatkan kepuasan pelanggannya.

\section{2 Metode Penelitian}

Metode pada penelitian ini memiliki beberapa alur proses yaitu :

\section{PLANNING $\Longrightarrow$ CONDUCTING $\Longrightarrow$ REPORTING}

Gambar 1. Tahapan Penelitian

Gambar 1. merupakan tahapan penelitian yang terdiri atas tahapan planning/rencana merupakan tahapan awal melakukan SLR, selanjtunya masuk ketahap Conducting yaitu tahap pelaksanaan dari SLR, dan tahapan terakhir yaitu Reporting/Laporan yang merupakan tahapan penulisan SLR menjadi sebuah laporan.

\section{2.1 Research Question}

Pada tahap ini ditentukan pertanyaan yang sesuai dengan topik penelitian. Berikut ini merupakan research question pada penelitian ini :

1. RQ1 : Apa nama aplikasi atau perusahaan penyedia jasa layanan telemedicine yang digunakan?

2. RQ2 : Apa metode yang digunakan untuk pengambilan data tentang menggapa menggunakan telemedicine?

3. RQ3 : Apa isu yang menjadi alasan penggunaan layanan telemedicine?

\section{2.2 Search Proces}

Search process merupakan tahap pencarian untuk mendapatkan sumber yang sesuai dengan pertanyaan penelitian yang relevan. Proses pencarian sumber dilakukan pada alamat situs https://scholar.google.co.id/.

\section{2.3 Inclusion and Exclusion Criteria}

Pada tahap ini yaitu ditentukannya kriteria dari data-data yang ditemukan, apakah data-data tersebut layak digunakan sebagai sumber data untuk penelitian atau tidak. Berikut ini merupakan kriteria sebuah data dikatakan layak menjadi sumber data penelitian yaitu :

1. Data yang diperoleh memiliki rentang waktu dari 2017 sampai 2021.

2. Data diperoleh dari sumber https://scholar.google.co.id/

3. Data yang digunakan hanya paper jurnal yang berkaitan dan relevan dengan kepuasan pelanggan terhadap layanan telemedicine.

\section{2.4 Quality Assesment}

Pada tahap ini data yang telah ditemukan akan dievaluasi berdasarkan pertanyaan berikut :

1. QA1 :Apakah paper jurnal diterbitkan pada rentang waktu 2017-2021?

2. QA2 : Apakah paper jurnal tersebut membahas penggunaan layanan telemedicine di Indonesia?

3. QA3 : Apakah paper jurnal tersebut menuliskan perusahaan telemedicine di Indonesia?

\section{HASIL DAN PEMBAHASAN}

3.1 Hasil Search Process dan Inclusion and Exclusion Criteria

\begin{tabular}{|l|c|c|}
\hline Search Keyword & Result & in accordance RQ \\
\hline $\begin{array}{l}\text { Penggunaan } \\
\text { Layanan } \\
\text { Telemedicine }\end{array}$ & 667 & 7 \\
\hline
\end{tabular}

Hasil dari search process dan inclusion and exclusion criteria yaitu hanya diambil 7 paper jurnal yang telah sesuai dengan kriteria yaitu paper jurnal diterbitkan pada rentang waktu 2017-2021 dan memiliki bahasan yang berkaitan dengan "Penggunaan Layanan" dan "telemedicine". Informasi yang didapatkan selanjutnya dikelompokkan menjadi beberapa jenis jurnal. Berikut ini merupakan tipe jurnal yang telah berhasil diperoleh :

Table 1 : Pengelompokan Berdasarkan Jurnal

\begin{tabular}{|l|l|l|l|}
\hline No & Tipe Jurnal & Tahun & Jumlah \\
\hline 1 & Jurnal Administrasi Bisnis (JAB) & 2021 & 1 \\
\hline 2 & Jurnal Komunikasi & 2021 & 1 \\
\hline 3 & Jurnal Ekonomi \& Bisnis & 2021 & 2 \\
\hline 4 & Seri Sains dan Teknologi & 2021 & 1 \\
\hline 5 & Jurnal Pengabdian dan Kewirausahaan & 2020 & 1 \\
\hline 6 & Jurnal Bisnis dan Manajemen & 2021 & 1 \\
\hline
\end{tabular}




\subsection{Hasil Quality Assesment}

Berikut ini merupakan hasil dari quality assessment yang dituliskan kedalam bentuk tabel :

Table 2 : Hasil Quality Assesment

\begin{tabular}{|l|l|l|c|c|c|c|}
\hline No & Penulis & Tahun & QA1 & QA2 & QA3 & Hasil \\
\hline 1 & Cynthia Fransiska dan Innocentius Bernarto & 2021 & YA & YA & YA & DITERIMA \\
\hline 2 & Genny Gustina Sari dan Welly Wirman & 2021 & YA & YA & YA & DITERIMA \\
\hline 3 & $\begin{array}{l}\text { Putu Aditya Putra dan I Gusti Ngurah Putra } \\
\text { Suryanata }\end{array}$ & 2021 & YA & YA & YA & DITERIMA \\
\hline 4 & Chrisanty V. Layman & 2021 & YA & YA & YA & DITERIMA \\
\hline 5 & $\begin{array}{l}\text { Maman Surahman, Nur Widiyasono dan } \\
\text { Rohmat Gunawan }\end{array}$ & 2021 & YA & YA & YA & DITERIMA \\
\hline 6 & Eko Retno Indriyarti dan Suryo Wibowo & 2020 & YA & YA & YA & DITERIMA \\
\hline 7 & $\begin{array}{l}\text { Vania Katherine Hermawan dan Eristia Lidia } \\
\text { Paramita }\end{array}$ & 2021 & YA & YA & YA & DITERIMA \\
\hline
\end{tabular}

\subsection{Data Analysis}

Pada tahap ini data-data dianalisis dan hasilnya dari analisa ini akan digunakan untuk menjawab Research Question (RQ) yang telah ditentukan sebelumnya dan akan membahas tentang isu-isu apa saja yang mempengaruhi penggunaan layanan telemedicine yang sering muncul dari tahun 2017-2021.

\section{3.1 Hasil Dari RQ1 : Nama Aplikasi}

Berdasarkan Research Question 1 atau RQ1 tentang nama aplikasi dari layanan telemedicine, maka dihasilkan kategori paper berdasarkan nama aplikasi yang diteliti. Dari hasil yang terlihat pada tabel 3 menunjukan bahwa saat ini banyak peneliti yang lebih memilih melakukan penelitian tentang kepuasan pelanggan pada layanan telemedicine Halodoc dan AloDoc. Sedangkan di posisi terakhir aplikasi KlikDokter menjadi aplikasi yang kurang diminati oleh peneliti untuk melakukan penelitian tentang kepuasan pelanggan terhadap layanan telemedicine.

Table 3 Kategori Nama Aplikasi

\begin{tabular}{|l|l|l|l|}
\hline no & $\begin{array}{l}\text { Nama } \\
\text { Aplikasi }\end{array}$ & Papper & Jumlah \\
\hline 1 & HaloDoc & {$[1],[2],[3],[4],[5],[6],[7]$} & 7 \\
\hline 2 & AloDoc & {$[2],[4],[5]$} & 3 \\
\hline 3 & KlikDokter & {$[4],[5]$} & 2 \\
\hline
\end{tabular}

\section{3.2 Hasil Dari RQ2 : Teknik Pengumpulan Data}

Berdasarkan Research Question 2 atau RQ2 tentang teknik pengumpulan data untuk penelitian kepuasan pelanggan telemedicine, didapatkan hasil yaitu kategori paper berdasarkan teknik pengumpulan datanya. Dari hasil yang terlihat dari tabel 4 menunjukan bahwa penelitian menggunakan teknik pengumpulan data kuesioner dan observasi. Untuk jumlah responden yang paling banyak digunakan oleh para peneliti sebanyak 201 responden dengan teknik pegumpulan data menggunakan kuesioner.

Tabek 4 Kategori Teknik Pengumpulan Data

\begin{tabular}{|c|l|c|c|c|}
\hline No & $\begin{array}{l}\text { Teknik } \\
\text { pengumpulan } \\
\text { data }\end{array}$ & $\begin{array}{l}\text { Jumlah } \\
\text { Responden }\end{array}$ & $\begin{array}{l}\text { Paper } \\
\text { Penelitian }\end{array}$ & Jumlah \\
\hline \multirow{2}{*}{1} & Kuesioner & 25 & {$[5]$} & 1 \\
\cline { 3 - 5 } & & 100 & {$[3],[4]$} & 2 \\
\cline { 3 - 5 } & & 190 & {$[6]$} & 1 \\
\cline { 3 - 5 } & & 201 & {$[1]$} & 1 \\
\hline 2 & Observasi & 6 & {$[2]$} & 1 \\
\hline
\end{tabular}

3.3.3 Hasil Dari RQ3: Faktor yang Mempengaruhi Kepuasan Pelanggan 
Berdasarkan Research Question 3 atau RQ3 tentang faktor yang mempengaruhi kepuasan pelanggan telemedicine, didapatkan hasil yaitu kategori paper berdasarkan faktor yang mempengaruhi kepuasan pelanggan. Dari hasil yang terlihat pada tabel 5 menunjukan bahwa kualitas pelayanan menjadi faktor yang paling mempengaruhi kepuasan pelanggan berdasarkan penelitian yang terdapat pada paper-paper tersebut. Selanjutnya faktor Efisien dan efektifitas applikasi menjadi faktor tertinggi kedua selanjutnya.

Table 5 Isu Penggunaan Layanan Telemedecine

\begin{tabular}{|c|l|l|c|}
\hline No & Isu yang di Bahas & Paper Penelitian & Jumah \\
\hline 1 & Kualitas Layanan & {$[1],[2],[3],[4],[5],[6],[7]$} & 7 \\
\hline 2 & Harga & {$[1],[4],[5],[6]$} & 4 \\
\hline 3 & Kualitas Sistem Informasi & {$[1],[4],[5],[7]$} & 4 \\
\hline 4 & Kualitas Informasi & {$[1],[2],[4],[5]$} & 4 \\
\hline 5 & Usia & {$[1],[4],[5]$} & 3 \\
\hline 6 & Pendidikan & {$[1],[4]$} & 2 \\
\hline 7 & Efisien \& Efektifitas Applikasi & {$[2],[3],[4],[5],[6]$} & 5 \\
\hline 8 & Brand Image & {$[2],[3],[5]$} & 3 \\
\hline 9 & Pemanfaatan Teknologi Informasi & {$[2],[5]$} & 2 \\
\hline 10 & Marketing Promotion & {$[3],[5],[6]$} & 3 \\
\hline
\end{tabular}

\subsection{Ringkasan Hasil Analisis Data}

Dari hasil tiap-tiap Research Question atau RQ, maka didapatkan informasi mengenai nama aplikasi, teknik pengumpulan data dan isu-isu penggunaan jasa telemedicine yang banyak muncul dan diteliti oleh para peneliti dari tahun 2017 sampai 2021. Maka dapat dilihat pada table 6 .

Table 6 Kategori Frekuensi Terbanyak RQ

\begin{tabular}{|c|l|l|}
\hline RQ & Aspek & Kategori Frekuensi Terbanyak \\
\hline 1 & Nama Aplikasi & HaloDoc \\
\hline 2 & Teknik Pengumpulan Data & Kuesioner (201 Responden) \\
\hline 3 & $\begin{array}{l}\text { isu terkini dari } \\
\text { penggunan layanan } \\
\text { Telemedicine }\end{array}$ & $\begin{array}{l}\text { Kualitas Pelayanan (penyediaan barang atau } \\
\text { jasa sesuai dengan keinginan atau yang } \\
\text { diharapkan oleh pelanggan ) }\end{array}$ \\
\hline
\end{tabular}

\section{KESIMPULAN}

Berdasarkan hasil dari penelitian yang telah dilakukan maka dapat diambil kesimpulan bahwa berdasarkan hasil Systematic Literature Review atau SLR, aplikasi layanan telemedicine yang paling banyak ditetiliti oleh para peneliti adalah HaloDoc lalu Teknik pengumpulan data yang paling banyak dilakukan adalah kuesioner dengan 201 responden. Serta isu yang paling banyak mempengaruhi penggunaan layanan telemedicine adalah kualitas layanan dari penyedia layanan telemedicine tersebut. Selain itu ditemukan 9 isu lainnya yang mempengaruhi penggunaan layanan telemedicine oleh pelanggan.

\section{DAFTAR PUSTAKA}

[1] Cynthia Fransiska dan Innocentius Bernato, "Pengaruh Kualitas Layanan terhadap Kepuasan Pelanggan dan Keberlanjutan Penggunaan pada Pengguna Aplikasi Kesehatan"Jurnal Administrasi Bisnis (JAB) Vol. 11. No. 2, 2021 (p-ISSN 2338-9605; e-2655-206X) 
[2] Genny Gustina Sari dan Welly Wirman "Telemedicine sebagai Media Konsultasi Kesehatan di Masa Pandemic COVID 19 di Indonesia” EISSN 2549-4902, ISSN 19784597 Volume 15 No 1 Maret 2021 (43-54) available https://journal.trunojoyo.ac.id/komunikasi.

[3] Putu Aditya Putra dan I Gusti Ngurah Putra Suryanata "SINERGI HALODOC DALAM MUTU PELAYANAN RUMAH SAKIT DI MASA PANDEMI COVID 19" $E$ JURNAL EKONOMI DAN BISNIS UNIVERSITAS UDAYANA. Vol. 10 No. 04, April 2021, pages: 211- 222. e-ISSN: 2337-3067. Available online at https://ojs.unud.ac.id/index.php/EEB/index.

[4] Chrisanty V. Layman, "PREDICTORS OF HALODOC'S USER SATISFACTION," Jurnal Muara Ilmu Ekonomi dan Bisnis, Vol. 5, No. 2, Oktober 2021 : hlm 348-361, ISSN-L 2579-6232.

[5] Maman Surahman, Nur Widiyasono dan Rohmat Gunawan, "ANALISIS USABILITY DAN USER EXPERIENCE APLIKASI KONSULTASI KESEHETAN ONLINE MENGGUNAKAN SYSTEM USABILITY SCALE DAN USER EXPERIENCE QUESTIONNAIRE,”Jurnal Siliwangi Vol.7. No.1, 2021. Seri Sains dan Teknologi. E-ISSN 2615-4765

[6] Eko Retno Indriyarti dan Suryo Wibowo, "BISNIS KESEHATAN BERBASIS DIGITAL: INTENSI PENGGUNA APLIKASI DIGITAL HALODOC," Jurnal Pengabdian dan Kewirausahaan Vol. 4 (No. 2) : no. 112 no. 121. Th. 2020 ISSN: 2581-2718 E-ISSN: 2620-3480, available:

https://journal.ubm.ac.id/index.php/pengabdiandankewirausahaan

[7] Vania Katherine Hermawan dan Eristia Lidia Paramita. "Faktor Yang Mempengaruhi Keberlanjutan Minat Pengguna Dalam Menggunakan Aplikasi mHealth Melalui Variabel Satisfaction," Jurnal Bisnis dan Manajemen. Volume 8 No 1 2021. Hlm. 150 - 166 Available: http://jurnal.unmer.ac.id/index.php/jbm.

[8] E. Triandini, S. Jayanatha, A. Indrawan, G. W. Putra, and B. Iswara, "Metode Systematic Literature Review untuk Identifikasi Platform dan Metode Pengembangan Sistem Informasi di Indonesia," Indones. J. Inf. Syst., vol. 1, no. 2, pp. 63-77, 2019. 